\title{
Optimizing Embedded Water Trades to Conserve Lakes in Arid and Semiarid Regions
}

\author{
Mohammad Ebrahim Banihabib ${ }^{1 *}$, Lubos Jurik², Mir Mohammad Azad Khorasani', \\ S. Mehdy Hashemy Shahdany ${ }^{1}$, Ali Mohammadi ${ }^{1}$, Jozefína Pokrývková ${ }^{2}$ \\ ${ }^{1}$ Department of Irrigation and Drainage, College of Aburaihan, University of Tehran, Pakdasht, Iran \\ ${ }^{2}$ Department of Water Resources and Environmental Engineering (WREE), \\ The Slovak University of Agriculture in Nitra, Nitra, Slovakia
}

Received: 23 July 2020

Accepted: 11 November 2020

\begin{abstract}
The shrinking of the former sixth largest salty lake in the world threatens the job security of farmers and life of inhabitants. We examined the capability of applying the optimal exchange of embedded water to release more water resources for the restoration of Lake Urmia. For this purpose, an optimization model is developed based on Kumar approach to maximize the income of the agricultural sector in the basin by deriving an optimal cropping pattern, embedded agricultural water imports and exports. Testing three cropping pattern policy discloses more income for the agriculture sector can be achieved by more flexible policy for cropping. The scenario which applies mild flexibility in cropping pattern policy and $80 \%$ availability of agricultural water, and scenario 6 which applies middle flexibility for cropping pattern policy and $60 \%$ availability of agricultural water are proposed for increasing the agricultural sector's income $7 \%$ and $21 \%$ and reducing water consumption in short term and long-term plans, respectively, for the restoration of the lake. These scenarios increase embedded agricultural water imports $164 \%$ and $161 \%$, and decrease agricultural water use $20 \%$ and $40 \%$, respectively. The model of this study can be future examined to restore drying lakes with high agricultural water use in their basins.
\end{abstract}

Keywords: embedded water, fuzzy model, Lake Urmia, optimization, restoration

\section{Introduction}

Several lakes are shrinking around the world due to climatic conditions and anthropogenic activities. The area of lakes in central- western Poland was reduced about $15 \%$ within 50 years [1]. On the other hand, saline lakes have $44 \%$ of the volume and $23 \%$ of

*e-mail: banihabib@ut.ac.ir the area among all the lakes in the world [2]. They are usually in arid and semi-arid countries [3]. These kinds of lakes are drying up rapidly due to climate change and anthropogenic activities [4]. Lake Urmia and the Aral Sea are among saline lakes which have been reduced to $10 \%$ of their original size in a half century. They caused dust storms and transmitted the pollutants from the dry lake bed causing severe health issues [4]. Therefore, it is environmentally crucial to find novel strategies to conserve lakes. 
Iran is a country with an arid and semi-arid climate with an average annual precipitation of $250 \mathrm{~mm}$ [5]. Water - related problems are considered one of the most fundamental environmental and socioeconomic challenges for the country. The demand for freshwater is increasing due population and life level growth in recent decades. Since agriculture in Iran and other countries is known as the main consumer of water resources [6], embedded water (virtual water) trading can be used for decreasing agricultural water. Growing agricultural water demands and climate change have produced water shortages in Lake Urmia, located in the north-west of Iran. The quick shrinkage of Lake Urmia has triggered an ecological tragedy that threatens the respiratory health of five million inhabitants due to salty dust storms from the dried part of the lake, and habitats of various species including 212 birds, 41 reptiles, 7 amphibians, and 27 mammals [7, 8]. A strategic plan based on sustainable development goals is needed for realizing sustainability for the lake $[9,10]$. Studies show that in spite of the aridity of the arid areas in Iran, these areas are net embedded water exporters [11]. Banihabib and Shabestari, (2017) developed a strategic plan for agricultural water demand management for arid regions and demonstrated a need for optimizing embedded agricultural water.

Embedded water is defined as the amount of water used to produce goods or services [13]. To optimally manage agricultural water, water scarce areas can get abundant embedded water through importing highwater-consuming crops, and at the same time they can lose less embedded water by exporting low water consuming crops [14]. On the other hand, countries which suffer from water stress can ensure the sustainability of their water resources by identifying goods which are cost-effective and have low embedded water content.

Several studies have been conducted on embedded water trading to examine embedded water management. Du Fraiture, (2004) examined the global grain exchange and its impact on water consumption. The results showed cereals importer countries trade 215 million ton of cereals in 1995 which without doing so, they had to withdraw $173 \mathrm{~km}^{3}$ of agricultural water from their internal water resources. In a study, Shi et al. [16] found that China was an embedded water importer from water- rich countries and an embedded water exporter to Africa. However, the embedded water import by this country was much higher than embedded water export. Masud et.al. (2019) analyzed historical (1985-2009) crop yields and embedded water content of three crops in Alberta, Canada. Results revealed that trade of (export/import) cereal crops from Alberta to more than a hundred countries led to the annual saving of 5 Billion Cubic Meters (BCM) of water during 1996-2005. These studies emphasized the significance of focusing on embedded water trading policies to achieve global sustainability. For sustainability in water resources, agricultural water use should be reduced. It can be decreased by decreasing high-water consume crops' area, and replacing them by low-water consume crops.

Linear programming is a crisp (non-fuzzy) method for optimization in operational research. This optimization method is still used as a practical method (in terms of application and structure) in selecting the optimal solution in various agricultural issues. The method has also been used in many studies in the field of agricultural water optimization. For instance, Dalin et al. (2015) focused on optimizing water consumption by irrigated lands. However, the uncertainty nature of the decision variable cannot be evaluated by crisp (nonfuzzy) models [19]. For this reason, fuzzy optimization approaches adopted by researchers to address the uncertainty nature of the decision variable. Bostani and Mohammadi, (2018) applied multi-objective and fuzzy programming to determine optimal cropping pattern. The results showed that applying fuzzy mathematical programming helps to determine an appropriate cropping pattern. Asaadi Mehrabani et al. (2018) used fully fuzzy linear programming for optimizing cropping pattern. The study revealed a $2.53 \%$ increase in net benefit compared to crisp optimization and $36.3 \%$ increase in comparison with the non-optimal net benefit of the agriculture sector. Banihabib and Shabestari, (2017) proposed a three-objective model to minimize aquifers water withdrawal and water demands, and maximize economic profit to optimally reallocate agricultural water. The use of a fuzzy optimization model to determine the optimal amount of embedded water exchange could be a new idea to improve water resources management in the basins suffering from water shortage.

Accordingly, the studies mentioned above have not focused on embedded water exchange as a management tool to optimize the cropping pattern and embedded agricultural water trade. Most studies considered nonfuzzy optimization for determining an optimal cropping pattern to enhance farmers' income in the basin. To conserve shrinking lakes in arid and semiarid regions, we need agricultural demand management to decrease water use and increase water flowing into the lakes. There is a question on the capability of applying optimal embedded water trading in releasing more water resources for the lake in arid regions. Moreover, we should find optimal cropping pattern and crops trading plan to implement optimized embedded water trade. By applying an optimal cropping pattern, less water will be used by the agricultural sector, and by applying optimal embedded water trading, more virtual water will be imported and less virtual water will be exported through agricultural product trading. In this paper, a fuzzy optimization model was developed for this purpose, and the model used Kumar approach to achieve optimal values. 


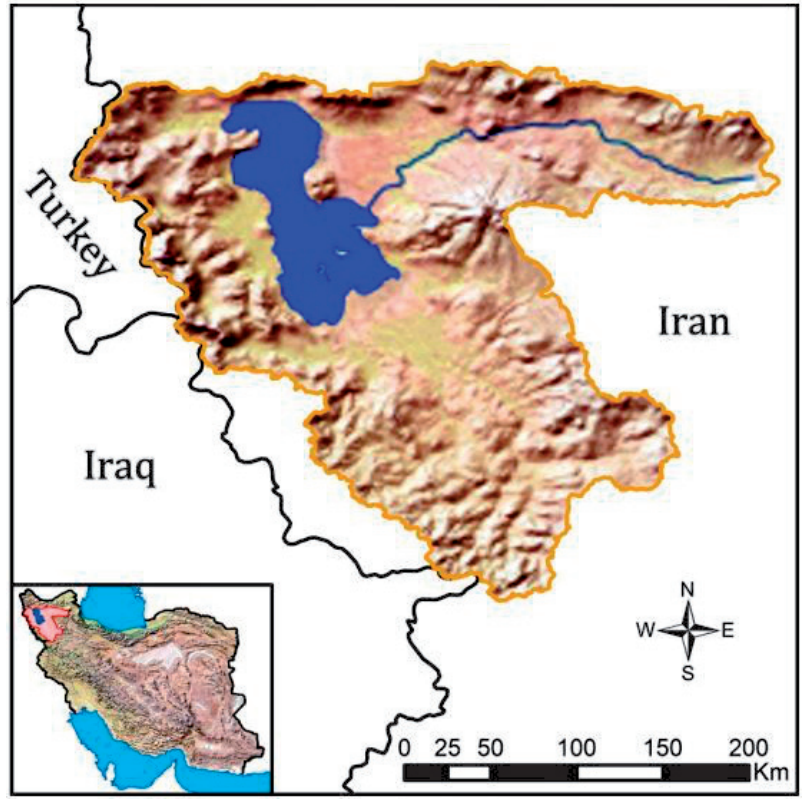

Fig. 1. Study area location [26].

\section{Material and Method}

Study Area

Lake Urmia is the largest lake in Iran, located in the northwest of Iran and positioned between $44^{\circ} 13^{\prime}-47^{\circ} 54^{\prime}$ East longitude and $35^{\circ} 40^{\prime}-38^{\circ} 29^{\prime}$ North latitude (Fig. 1). The lake is an internationally protected area as a registered UNESCO Biosphere Reserve and a Ramsar site [21, 22]. The Iranian Department of Environment designated most of the 102 Lake Urmia's islands and its wetlands as national park areas. Fig. 2 shows shrinking history of the lake, and Figs 3 and 4 illustrate photos of the dried area of the lake. The shrinking of the former sixth largest salty lake in the world threatens the job security of approximately 1.5 million farmers and 8.3 million inhabitants in the north of Iran. In the Urmia Basin, significant population growth has increased competition for agricultural water, and thus caused intensive water scarcity and lake shrinkage. The regional water use has been changed

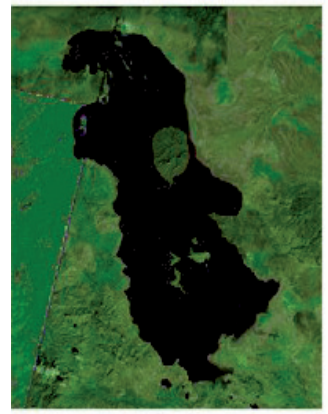

1972

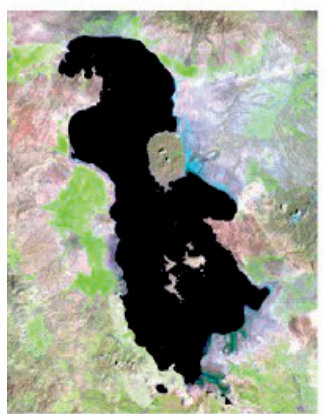

2000

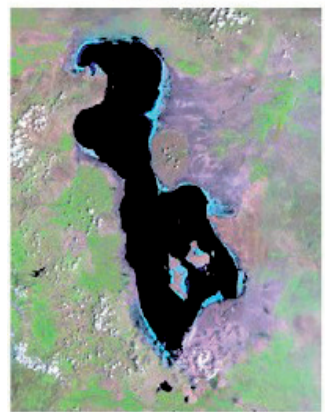

2012

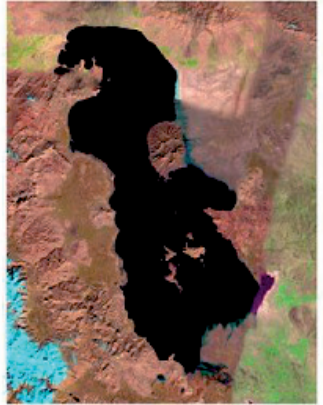

1984

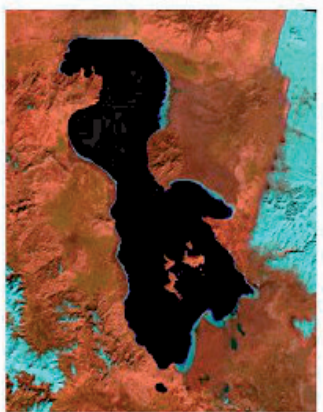

2002

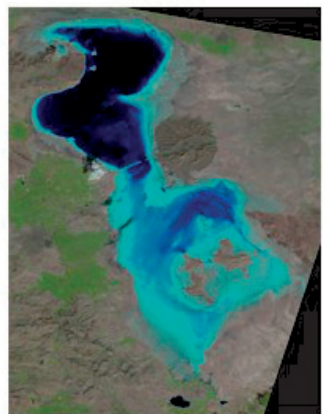

2013

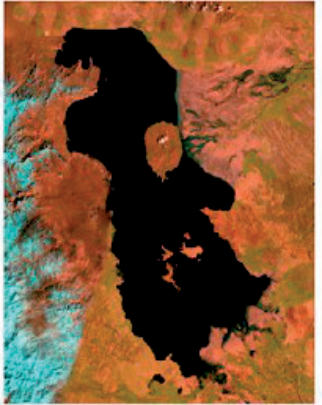

1987

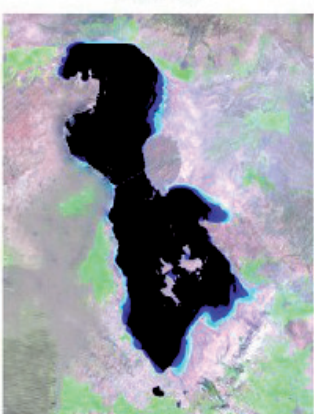

2006

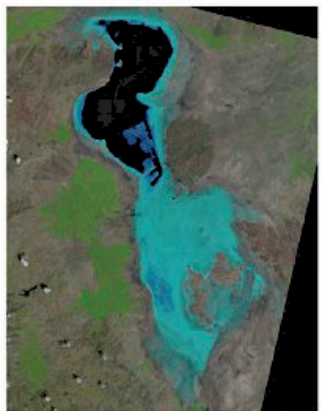

2014

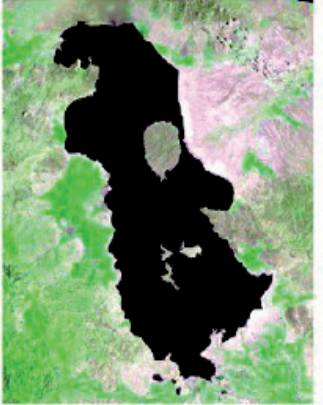

1989

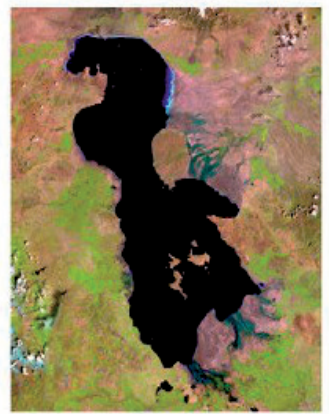

2009

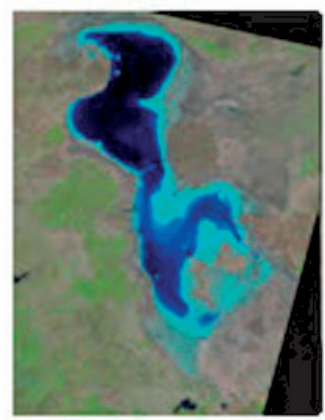

2015

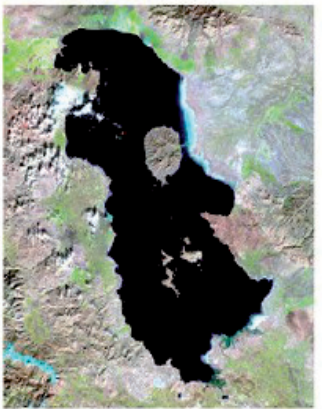

1998

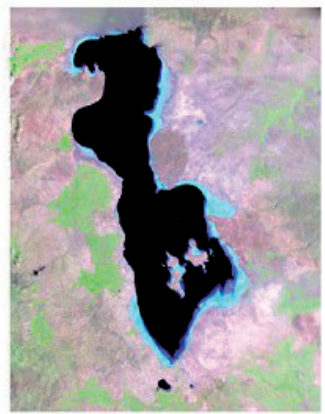

2011

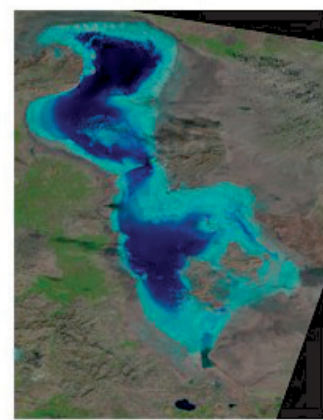

2018

Fig. 2. Land sat image of Lake Urmia [27]. 


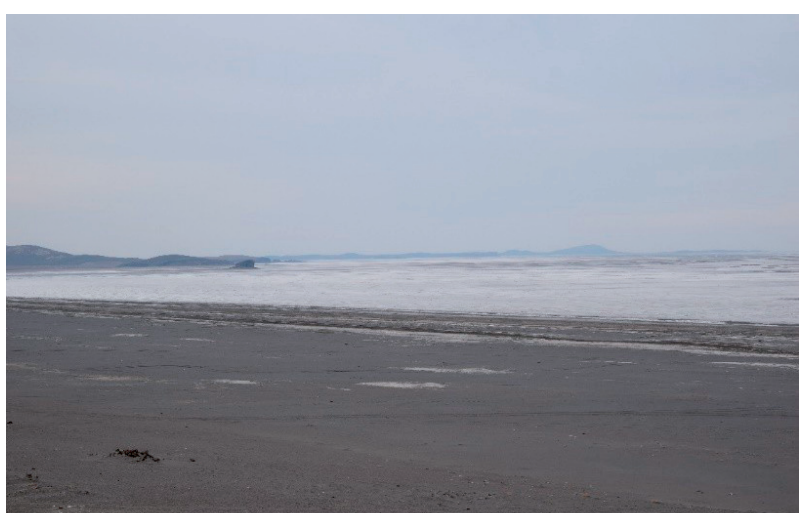

Fig. 3. A view of dried part of Lake Urmia.

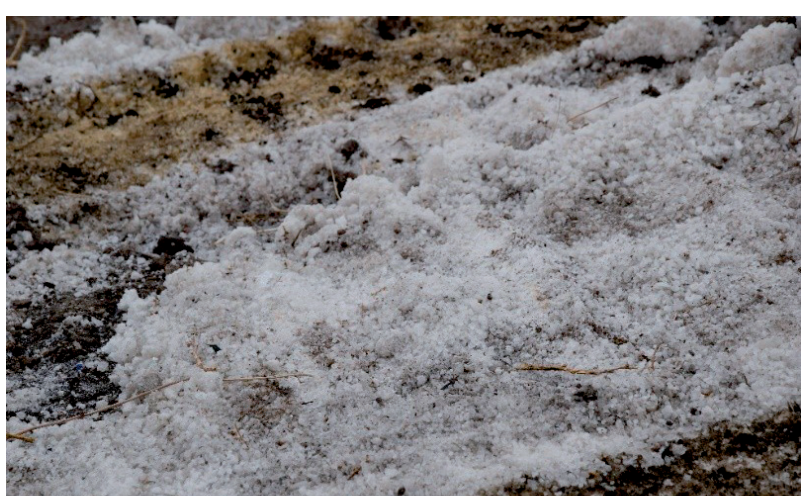

Fig. 4. A close up of salt on the dried part of the lake. significantly in the lake basin [23]. Fathian et al. (2014) showed that the long-term trend of rapidly declining lake level began in 1996, and predicted that the lake will be entirely dried within about 10 years, if current basin condition continues. The Iranian Department of Environment reports that the lake requires a minimum inflow of 3.1 million cubic meter per year (2010) to be ecologically stable. For this purpose, $40 \%$ of the agricultural water should be reduced [25] .

\section{Research Methods}

The crop production, import, and export, sales prices of the products and production costs in the study period (2008-2017) were from the Iran ministry of agriculture, the statistical center of Iran and ministry of roads and urban development (customs and terminals administration department). On the next level, a fuzzy optimization model was developed for embedded water trading. The flowchart for the development of the optimization model is shown in Fig. 5.

\section{Optimization Model}

Fuzzy logic has been established to consider a range of possibilities rather than definite values in the simulation of water resources [28]. Since the water use and economical factor of optimization have a range of variation rather than definite values, in this

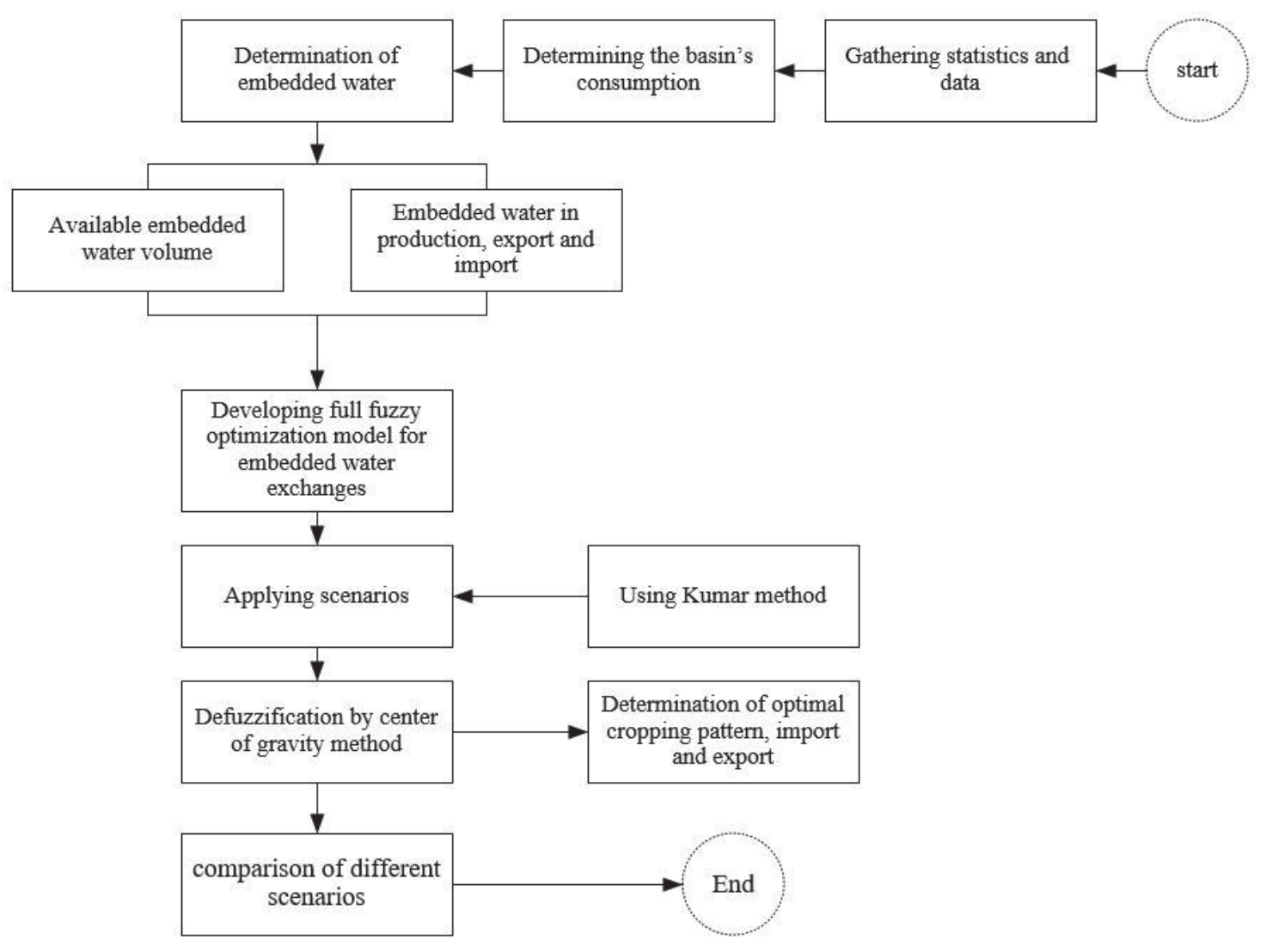

Fig. 5. Research flowchart. 
research, to address the range of parameter variation, a fuzzy optimization model was developed. The objective function maximizes basin's income shown as Equation (1).

$$
\begin{aligned}
M A X: & \widetilde{N B^{ \pm}}=\sum_{i=1}^{n} \tilde{B}_{E i}\left(W_{E i}\right)+\sum_{i=1}^{n} \tilde{C}_{u i}\left(W_{C i}\right) \\
& -\sum_{i=1}^{n} \tilde{C}_{I i}\left(W_{I i}\right)-\sum_{i=1}^{n} \tilde{C}_{p i}\left(W_{P i}\right)
\end{aligned}
$$

$\widetilde{N B^{ \pm}}$is the Net Benefit of the basin in a fuzzy form, $\tilde{B}_{E_{i}}$ is the fuzzy benefit of exported crop $i$ from the basin, is the fuzzy benefit of sold crop $i$ in the basin, $\tilde{C}_{I_{i}}$ is the fuzzy cost of imported crop $i$ to the basin, $\tilde{C}_{P_{i}}$ is the production cost of crop $i$ in the basin. $W_{E_{i}}$ is the embedded water of exported crop $i$ from the basin, $W_{C_{i}}$ is the embedded water of sold crop $i$ in the basin, $W_{I_{i}}$ is the embedded water of imported crop $i$ to the basin, $W_{P_{i}}$ is the embedded water of produced crop $i$ in the basin. These four groups of variables are decision variables of the optimization. The embedded water for producing a crop $\left(W_{P_{i}}\right)$ has a direct relationship with the crop area, and thus optimal values of crop area can be determined using the optimization model. These areas are called an optimal cropping pattern. Embedded water crop $i$ is determined based on the crop water requirement for crop $i$ as follows (Ehsani et al., 2009):

$$
\mathrm{EW}_{\mathrm{i}}=\left(\frac{\overline{\mathrm{CWR}_{1}}}{\lambda_{\mathrm{i}}}\right)
$$

...where $\mathrm{EW}_{\mathrm{i}}$ is the embedded water for each crop $\left(\mathrm{m}^{3} /\right.$ ton), $\overline{\mathrm{CWR}_{1}}$ is the water requirement of crop $i$ $\left(\mathrm{m}^{3} / \mathrm{ha}\right)$, and $\lambda_{i}$ (ton/ha) is yield of the crop $i$. For each crop, $W_{E_{i}}, W_{I_{i}}$, and $W_{C_{i}}$ were determined by multiplying $\mathrm{EW}_{\mathrm{i}}$ by exported, imported and consumed weight of the crop.

Four types of constraints are considered for the optimization purposes which are as follows:

a) The embedded water balance for each crop exchange:

This constraint balances imported, exported, produced and consumed crops in the basin. This means the consumed weight of each crop plus the exported weight of the crop should be balanced by the produced weight of the crop plus the imported weight of the crop. Since the crops have embedded water, this balance can be rearranged as a balance for the embedded water for each crop.

b) The limitation of available water in the basin: The average available water equals 2.2 billion cubic meters for the agricultural sector [29]. Therefore, the available water volume should be balanced by the embedded water in produced crops, exportation, and importation as follows:

$$
A W^{ \pm} \geq \sum_{i=1}^{n} W_{E i}+\sum_{i=1}^{n} W_{C i}
$$

...where, AW is the available water for the agriculture sector in the basin (in terms of cubic meters). Limiting the total cultivated area: since total arable land is limited, the total cropping land in the optimization should be limited to the current total arable land.

c) Cropping pattern policies: Since changing cropping pattern is limited by the culture of farmers in the study area three policies formed after numerous meetings with local experts and regional managers of the study area as follows:

1. The first cropping pattern policy, with mild flexibility in constraints, was considered since current crop production cannot be eliminated or multiplied immediately because current farming culture should be regarded in a short period implementation (e.g., a five-year plan). In this policy, for wheat, vegetables (carrots, coriander, eggplant, lettuce, cabbage, other vegetables), barley, forage (forage corn, straw, clover, alfalfa, others), corn are limited to $10 \%$ reduction and $20 \%$ increase in the optimization since these crops are strategical for dairy foods or fresh use. For kiwi, rice, olive, citrus (lemon, orange, tangerine, and another citrus), the policy keeps current production, since these crops are relatively high water demanding crops and increasing these trees in a short period will not be possible. For onion, sugar beet, cucurbits (cucumber, watermelon, melon, and other cucurbits), apple, oilseeds (soybean), tomato, legume (split pea, bean, legume, lentil) cantaloupe, pomegranate, oranges, plum, potato, apricot, hazelnut, cherry, sour cherry, grape, walnut, peach, quince, almond, pistachio, medicinal herbs (German chamomile, hyssops, cypresses and damask rose) mushroom, pear, fig, sumac, olive, mulberry, barberry, blueberry, aglet and nectarine are limited to $50 \%$ reduction and $100 \%$ increase in the optimization, since these crops have proper price elasticity and market.

2. The second cropping pattern policy, with middle flexibility in constraints, constrains all crop production to be between 0.1 and 10 times of the current productions for the medium-term period (e.g., until the end of the second 5-year plan).

3. In the third cropping pattern policy, with full flexibility in constraints, there is no restriction for a crop, and this is designed to maximize the basin's income for limited water in the basin. Moreover, the implantation of this policy would be required in a long-term period concerning limited water resources in the basin.

\section{Kumar Approach}

Kumar's approach is used to develop a fuzzy optimization model in this study. In this approach, fuzzy numbers are triangular with the following characteristics:

If $\tilde{A}$ and $\tilde{B}$ were two triangular fuzzy numbers with upper, middle and lower fuzzy bounds as (a.b.c) and (d.e.f), respectively. A triangular fuzzy number, unlike 
a crisp value, uses three numbers to define a value between 0 and 1 . Triangular function was defined by a lower limit $a$, an upper limit $c$, and $a$ value $b$, where $a<b<c$. The membership is zero at $a$, and linearly increases to its maximum value $(=1)$ at $b$, and the linearly decreases to zero at $c$. The main operations for fuzzy number are as follows:

$$
\left\{\begin{array}{l}
\tilde{A}=(a \cdot b \cdot c) ; \tilde{B}=(\text { d.e.f }) \\
\tilde{A}+\tilde{B}=(a+d \cdot b+e \cdot c+f) \\
\tilde{A} * \tilde{B}=(\text { ad. be.cf })(\text { if } a . d \geq 0)
\end{array}\right.
$$

Using the main operations of Equation (4), Equation (1) can be rearranged as Equation (5) by replacing all parameters optimization and fuzzy decision variables $\left(W_{E_{i}}, W_{I_{i}}, W_{P_{i}}\right.$ and $\left.W_{C_{i}}\right)$ :

$$
M A X: \widetilde{N B^{ \pm}}=\left(s_{i j}, 2 t_{i j}, u_{i j}\right)
$$

...where, $u_{i j}, t_{i j}$ and $s_{i j}$ are upper, middle and lower fuzzy numbers of $\overparen{N B^{ \pm}}$which can be determined by applying fuzzy operations on Equation (1).

Kumar's approach uses Equation (6) to convert fuzzy optimization to linear crisp programming.

$$
M A X z=\sum_{j=1}^{n} 0.25\left(s_{i j}+2 t_{i j}+u_{i j}\right)
$$

Since fuzzy numbers $\left(s_{i j}, 2 t_{i j}, u_{i j}\right)$ are function of decision variables $\left(W_{E_{i}}, W_{I_{i}}, W_{P_{i}}\right.$ and $\left.W_{p C_{i}}\right)$, the solving this equation together with constraints, $W_{E_{i}}$ is the embedded water export of crop $i, W_{I_{i}}$ is the embedded water import of crop $i, W_{p_{i}}$ is the embedded water production of crop $i$.

\section{Optimization Scenarios}

In this study, 9 optimization scenarios were defined based on three factors, including three cropping pattern policy (as explained above) and three available water (100\% (status quo), $80 \%$ and $60 \%$ of the current water use) as shown in Fig. 6. The Urmia Lake Restoration Program (ULRP) planned a $40 \%$ reduction in agricultural water consumption to restore the lake which is the main reason for defining $60 \%$ available water scenarios. Since accomplishing $40 \%$ saving in water resources is a long-term measure, the scenarios with $20 \%$ reduction in agricultural water use $(80 \%$ available water scenarios) were defined too. Moreover, $100 \%$ available water scenarios were examined for comparison purpose.

\section{Result and Discussion}

Testing 3 cropping pattern policy reveals more income for the agriculture sector can be achieved by more flexible policy for cropping. Fig. 7a) shows the

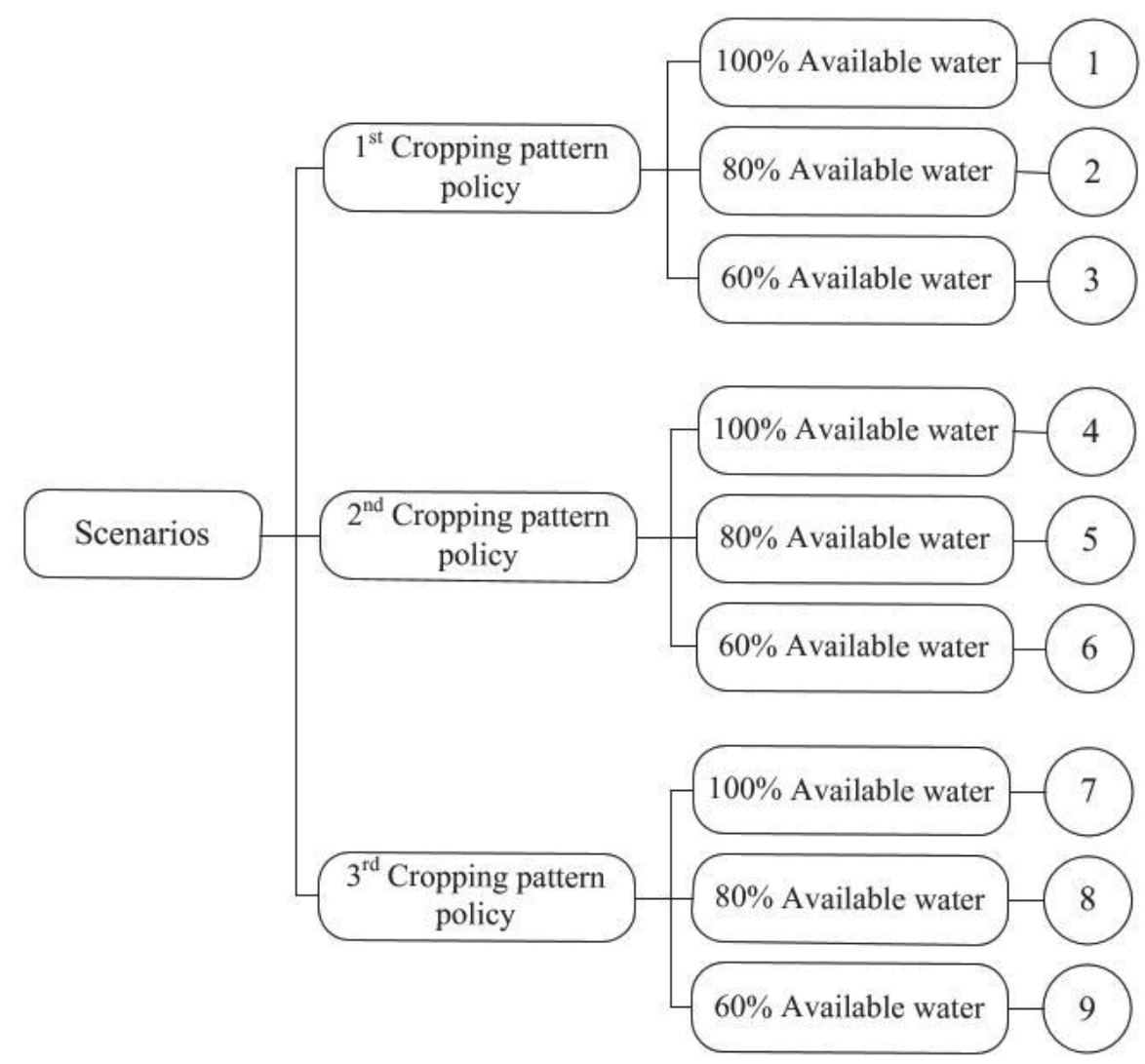

Fig. 6. Defining scenarios. 
a)

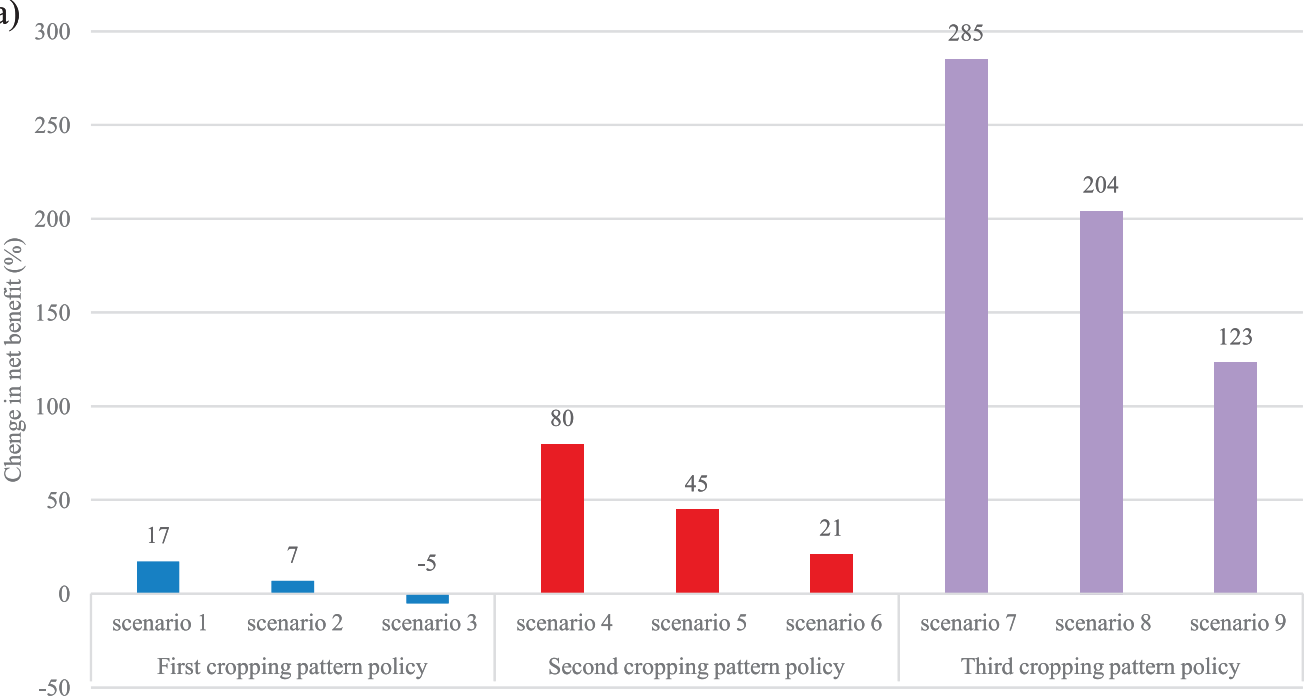

@Water consumption $\quad$ Net import embedded water

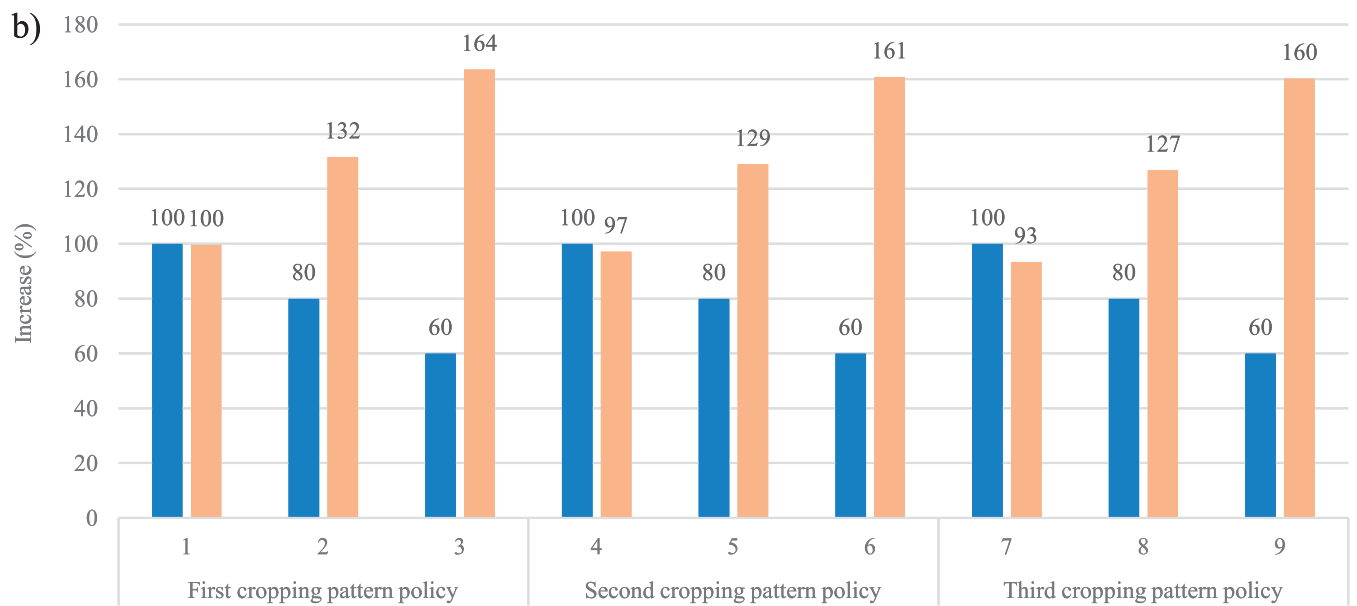

Fig. 7. Changes in a) net benefit of farmers, b) water consumption and net import embedded water in the study basin.

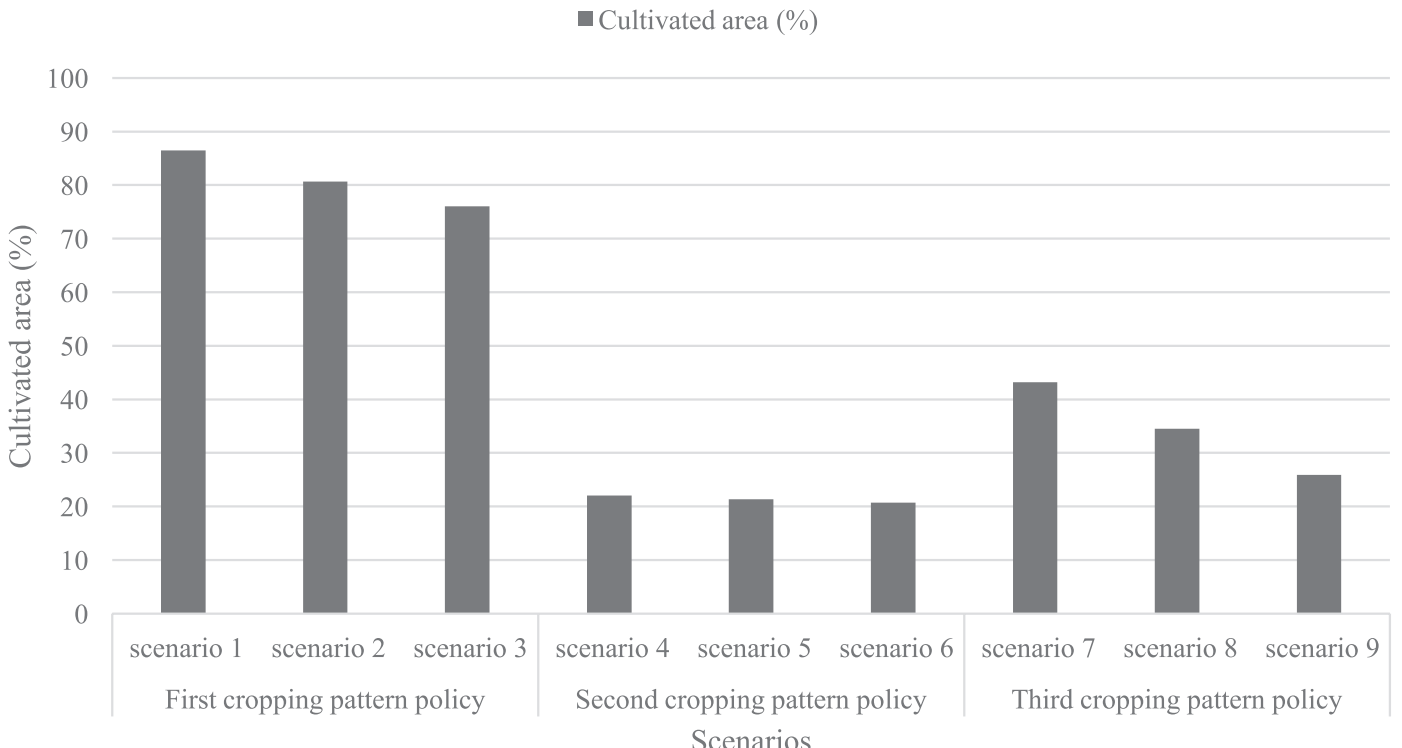

Fig. 8. Percentage of cultivated are in the scenarios. 
income of the agricultural sector in 12 optimization scenarios. Third, second and first cropping pattern policy which, respectively, apply more flexible constraints in determining cropping pattern, will produce more income for the farmers in the basin. Reduction in the available water in scenarios in each cropping pattern policy causes a decrease in the income. All scenarios have positive effect in earning income by the agricultural sector except the scenario 3 which decreases the income by 5\% due applying $40 \%$ reduction in available water for farming. As constraints become more flexible from first to third cropping pattern policy, the income of agricultural sector increases considerably and embedded water import decreases slightly.

The agricultural sector of the study area earns more income by applying the optimal cropping pattern and optimized trading of embedded water (Fig. 7a). The optimal cropping pattern reduces water use in the agricultural sector, and more embedded agricultural water should be imported to admit the needed agricultural crops in the study area (Fig. 7b). The need to import embedded agricultural water increases slightly by applying first, second and third cropping pattern policy, respectively, and grows considerably by in decreasing available water in each cropping pattern policy i.e., scenario 1-3 in the first policy, i.e. scenario 4-6 in the second policy, i.e. scenario 7-9 in the third policy. Analyzing the results of 12 optimization scenarios shows that even by decreasing available water, it is possible to increase income of the agricultural sector and provide more water for the restoration of the lake except scenario 3 (i.e., applying first cropping

Table 1. Horticultural crops water use in current condition and scenarios (\%).

\begin{tabular}{|c|c|c|c|c|c|c|c|c|c|c|}
\hline Crop & Current & $\begin{array}{c}\text { Scenario } \\
1\end{array}$ & $\begin{array}{c}\text { Scenario } \\
2\end{array}$ & $\begin{array}{c}\text { Scenario } \\
3\end{array}$ & $\begin{array}{c}\text { Scenario } \\
4\end{array}$ & $\begin{array}{c}\text { Scenario } \\
5\end{array}$ & $\begin{array}{c}\text { Scenario } \\
6\end{array}$ & $\begin{array}{c}\text { Scenario } \\
7\end{array}$ & $\begin{array}{c}\text { Scenario } \\
8\end{array}$ & $\begin{array}{c}\text { Scenario } \\
9\end{array}$ \\
\hline Apple & 4 & 2 & 2 & 2 & 0 & 0 & 0 & 0 & 0 & 0 \\
\hline Citrus fruits & 0 & 0 & 0 & 0 & 0 & 0 & 0 & 0 & 0 & 0 \\
\hline Pomegranate & 0 & 0 & 0 & 0 & 0 & 0 & 0 & 0 & 0 & 0 \\
\hline Plum & 1 & 0 & 0 & 0 & 0 & 0 & 0 & 0 & 0 & 0 \\
\hline Apricot & 1 & 2 & 1 & 1 & 4 & 4 & 4 & 0 & 0 & 0 \\
\hline Hazelnut & 0 & 0 & 0 & 0 & 0 & 0 & 0 & 0 & 0 & 0 \\
\hline Cherry & 0 & 0 & 0 & 0 & 2 & 2 & 2 & 0 & 0 & 0 \\
\hline Sour Cherry & 0 & 0 & 0 & 0 & 0 & 0 & 0 & 0 & 0 & 0 \\
\hline Grapes & 11 & 20 & 5 & 5 & 1 & 1 & 1 & 0 & 0 & 0 \\
\hline Walnut & 0 & 1 & 0.5 & 0 & 1 & 1 & 1 & 0 & 0 & 0 \\
\hline Peach & 1 & 0 & 0 & 0 & 0 & 0 & 0 & 0 & 0 & 0 \\
\hline Quincunx & 0 & 0 & 0 & 0 & 0 & 0 & 0 & 0 & 0 & 0 \\
\hline Almond & 0 & 0 & 0 & 0 & 0 & 0 & 0 & 0 & 0 & 0 \\
\hline Pistachios & 0 & 0 & 0 & 0 & 0 & 0 & 0 & 0 & 0 & 0 \\
\hline Pear & 0 & 0 & 0 & 0 & 0 & 0 & 0 & 0 & 0 & 0 \\
\hline Fig & 0 & 0 & 0 & 0 & 0 & 0 & 0 & 0 & 0 & 0 \\
\hline Sea-buckthorn & 0 & 0 & 0 & 0 & 0 & 0 & 0 & 0 & 0 & 0 \\
\hline Mulberry & 0 & 0 & 0 & 0 & 0 & 0 & 0 & 0 & 0 & 0 \\
\hline Blueberries & 0 & 0 & 0 & 0 & 0 & 0 & 0 & 0 & 0 & 0 \\
\hline Olive & 0 & 0 & 0 & 0 & 0 & 0 & 0 & 0 & 0 & 0 \\
\hline Hawthorn & 0 & 0 & 0 & 0 & 0 & 0 & 0 & 0 & 0 & 0 \\
\hline Nectarine & 0 & 0 & 0 & 0 & 0 & 0 & 0 & 0 & 0 & 0 \\
\hline Kiwi & 0 & 0 & 0 & 0 & 0 & 0 & 0 & 0 & 0 & 0 \\
\hline Total crops & 20 & 27 & 11 & 10 & 9 & 8 & 8 & 0 & 0 & 0 \\
\hline Dominant crops & 16 & 24 & 9 & 8 & 8 & 8 & 8 & 0 & 0 & 0 \\
\hline
\end{tabular}

Dominant Horticultural crops are the crops with at least $1 \%$ water use of current available agricultural water. 
Table 2. Agricultural crops water use in current condition and scenarios (\%).

\begin{tabular}{|c|c|c|c|c|c|c|c|c|c|c|}
\hline Crop & Current & $\begin{array}{c}\text { Scenario } \\
1\end{array}$ & $\begin{array}{c}\text { Scenario } \\
2\end{array}$ & $\begin{array}{c}\text { Scenario } \\
3\end{array}$ & $\begin{array}{c}\text { Scenario } \\
4\end{array}$ & $\begin{array}{c}\text { Scenario } \\
5\end{array}$ & $\begin{array}{c}\text { Scenario } \\
6\end{array}$ & $\begin{array}{c}\text { Scenario } \\
7\end{array}$ & $\begin{array}{c}\text { Scenario } \\
8\end{array}$ & $\begin{array}{c}\text { Scenario } \\
9\end{array}$ \\
\hline Onion & 13 & 25 & 22 & 6 & 82 & 62 & 42 & 0 & 0 & 0 \\
\hline Sugar beet & 7 & 3 & 3 & 3 & 1 & 1 & 1 & 0 & 0 & 0 \\
\hline $\begin{array}{l}\text { Kitchen garden } \\
\text { crops }\end{array}$ & 1 & 1 & 0 & 0 & 0 & 0 & 0 & 0 & 0 & 0 \\
\hline Wheat & 20 & 18 & 18 & 17 & 2 & 2 & 2 & 0 & 0 & 0 \\
\hline Oily seeds & 0 & 0 & 0 & 0 & 0 & 0 & 0 & 0 & 0 & 0 \\
\hline Tomato & 1 & 0 & 0 & 0 & 0 & 0 & 0 & 0 & 0 & 0 \\
\hline Vegetables & 0 & 0 & 0 & 0 & 1 & 1 & 1 & 0 & 0 & 0 \\
\hline Beans & 23 & 12 & 12 & 11 & 2 & 2 & 2 & 0 & 0 & 0 \\
\hline Cantaloupe & 0 & 0 & 0 & 0 & 0 & 0 & 0 & 0 & 0 & 0 \\
\hline Barley & 5 & 5 & 5 & 5 & 1 & 1 & 1 & 0 & 0 & 0 \\
\hline Potato & 3 & 1 & 1 & 1 & 0 & 0 & 0 & 0 & 0 & 0 \\
\hline Alfalfa & 6 & 6 & 6 & 5 & 1 & 1 & 1 & 0 & 0 & 0 \\
\hline Mushroom & 0 & 0 & 0 & 0 & 0 & 0 & 0 & 100 & 80 & 60 \\
\hline $\begin{array}{l}\text { Medicinal } \\
\text { plants }\end{array}$ & 0 & 0 & 0 & 0 & 0 & 0 & 0 & 0 & 0 & 0 \\
\hline Sumac & 0 & 0 & 0 & 0 & 0 & 0 & 0 & 0 & 0 & 0 \\
\hline Barberry & 0 & 1 & 0 & 0 & 2 & 2 & 2 & 0 & 0 & 0 \\
\hline Corn & 0 & 0 & 0 & 0 & 0 & 0 & 0 & 0 & 0 & 0 \\
\hline Rice & 0 & 0 & 0 & 0 & 0 & 0 & 0 & 0 & 0 & 0 \\
\hline Total crops & 80 & 73 & 69 & 50 & 91 & 72 & 52 & 100 & 80 & 60 \\
\hline Dominant crops & 77 & 69 & 66 & 47 & 88 & 68 & 48 & 100 & 80 & 60 \\
\hline
\end{tabular}

Dominant agricultural crops are the crops with at least $2 \%$ water use of current available agricultural water.

pattern policy and $60 \%$ availability of agricultural water) which reduces the income by $5 \%$.

The results of optimized cropping pattern in examined scenarios show that the cultivated area in optimization scenarios affected by water availability and cropping pattern policies (Fig. 8). This figure also illustrates that cultivated areas in optimization scenarios are decreased by reducing available water. The biggest reduction in cultivated area achieved by applying the second cropping pattern, followed by third and first policy, respectively. Assuming practicing current farming culture and the direct relation of the number of farming jobs to cultivated area in the study basin, applying second, third and first cropping pattern policies can affect more on the number of farming jobs, respectively, which should be addressed in the proposing optimal cropping pattern and embedded agricultural trades.

Since the proposed cropping pattern will affect farming culture of the study area, detail of optimized cropping pattern should be analyzed to decide the proposed cropping pattern and embedded agricultural water trade for the restoration of the lake. Table 1 illustrates the percentage of agricultural water consumed by horticultural crops in the current condition and 12 optimization scenarios. The dominant crops which use at least $1 \%$ of available agricultural water highlighted in the table. In the current condition, four horticultural crops (apple, plum, apricot and grapes) are dominant crops which totally consume 16\% of available agricultural water (Table 1). By applying the third cropping pattern policy, all horticultural crops omitted from optimal cropping pattern (Table 1). By applying second cropping pattern policy (optimization scenarios 4-6), optimal cropping pattern of horticultural crops omits apple and plum from current horticultural cropping, and focuses on the cultivation of apricot, cherry, walnut and grapes (Table 1). Similarly, implementing optimization scenarios of first cropping pattern policy replaces plum by walnut (Table 1). The scenarios of both first and second cropping pattern policies (scenarios 1-6) could be implemented from view point horticulture cropping. Thus, the priority of these policies should be examined for agricultural 
cropping. Table 2 shows percentage of agricultural water consumed by agricultural crops in the current condition and 12 optimization scenarios. The dominant crops which use at least $2 \%$ of available agricultural water highlighted in the table. In the current condition, seven agricultural crops (onion, sugar beet, wheat, beans, barley, potato and alfalfa) are dominant crops which totally consume $77 \%$ of available agricultural water (Table 2). By applying the third cropping pattern policy, all crops omitted from the optimal cropping pattern except mushrooms which need the least water among the corps. Changing agriculture in the study area to single crop is impractical, and thus this policy cannot be implemented (Table 2). By applying second cropping pattern policy (optimization scenarios 4-6), dramatic change occurred in cropping of strategic crops (i.g., wheat, barley, alfalfa, beans). This means strategic crops like wheat, barley, alfalfa, beans should be imported to admit the needs of inhabitants in the basin which need long term planning, and cannot be proposed for near future (Table 2). By applying in first cropping pattern policy (optimization scenarios 1-3), the potato will be omitted from dominant crops in the current cropping, and dramatic change happens in agricultural water used by increasing in onion cultivation and decreasing in beans cultivation. The second scenario of this policy optimizes the income of the agricultural sector (Fig. 7a), and decreases agricultural water use without causing dramatic decrease in strategic crops. Thus, this scenario can be proposed for implementation in a short-term plan (Table 2). Area and number of dominant crops are, respectively, reduced by third, second and first cropping pattern policy and decreasing available water. Since dramatic change in farming culture is impossible, scenario 2 and scenario 6 are, respectively, proposed for reducing water consumption and agricultural water trade in short term and long-term plans for restoration of the lake.

\section{Conclusion}

In addition to traditional measures, to provide water for restoring lakes, novel measures like an optimal embedded water management and cropping pattern can be examined for this purpose. In this study, a fuzzy optimization model was developed for driving the optimal embedded water trade and cropping pattern to provide water for the conserving lakes in arid and semiarid regions. Applying the proposed model to Lake Urmia basin following main points can be concluded:

- By applying more flexible constraints in the optimization cropping pattern, the income of the agricultural sector increases considerably and the embedded water import decreases slightly.

- It is possible to increase income of the agricultural sector and provide more water for the restoration of the lake by all 12 optimization scenarios. The exception is scenario 3 with $5 \%$ reduction in income which applies first cropping pattern policy and 60\% availability of agricultural water.

- Assuming practicing current farming culture and the direct relation of the number of farming jobs to the cultivated area in the study area, applying second, third and first cropping pattern policies can affect more on the number of farming jobs, respectively, which should be addressed in the proposing optimal cropping pattern and embedded agricultural trades.

- The scenario 2 (applying first cropping pattern policy and $80 \%$ availability of agricultural water) and scenario 6 (applying second cropping pattern policy and $60 \%$ availability of agricultural water) are, respectively, proposed for increasing the agricultural sector's income $7 \%$ and $21 \%$ and reducing water consumption in short term and long-term plans for the restoration of the lake. These scenarios decrease agricultural water use $20 \%$ and $40 \%$, and increases embedded agricultural water imports $164 \%$ and $161 \%$, respectively.

Even though agricultural product exchanges between the study basin and other parts of Iran can balance the agricultural product prices, but, in future studies the price elasticity of agricultural products should be taken into account to address price change due increasing or decreasing production of crops. The proposed model in this study can be examined to develop an optimal cropping pattern and embedded water trading to conserve drying lakes with high agricultural water use in their basins.

\section{Acknowledgement}

This research received a grant from University of Tehran 13-GASPU-2021 Blue-green infrastructure as a basis for climate adaptation of land management in agricultural and urbanized land.

\section{Conflict of Interest}

The authors declare no conflict of interest.

\section{References}

1. CHOIŃSKI A., PTAK M., ŁAWNICZAK A.E. Changes in water resources of Polish lakes as influenced by natural and anthropogenic factors. Polish Journal of Environmental Studies, 25 (5), 1883, 2016.

2. WURTSBAUGH W.A., MILLER C., NULL S.E., JUSTIN DE ROSE R., WILCOCK P., HAHNENBERGER M., MOORE J. Decline of the world's saline lakes. Nature Geoscience, 10 (11), 816, 2017.

3. JELLISON R., WILLIAMS W.D., TIMMS B., ALCOCER J., Aladin N.V. Salt lakes: Values, threats and future. In Aquatic Ecosystems: Trends and Global Prospects (pp. 94-110). Cambridge University Press, 2008.

4. TUSSUPOVA K., ANCHITA HJORTH P., MORAVEJ M. Drying lakes: A review on the applied restoration 
strategies and health conditions in contiguous areas. Water (Switzerland), 12 (3), 749, 2020.

5. PASHAKI M.H.K., KHOSROJERDI A., SEDGHI H., HOSSEIN M., PASHAKI K., KHOSROJERDI A., SEDGHI H. Virtual water strategy and its application in optimal operation of water resources. Journal of Applied Research in Water and Wastewater, 8 (2), 349, 2017.

6. YOUSEFI H., MOHAMMADI A., MIRZAAGHABEIK M., NOOROLLAHI Y. Virtual water evaluation for grains productsin Iran Case study: Pea and bean. Journal of Water and Land Development, 35 (1), 275, 2017.

7. REZVANTALAB S., AMROLLAHI M.H. Investigation of Recent Changes in Urmia Salt Lake. International Journal, 2 (3), 2, 2011.

8. The Iranian Department of Environment. Urmia Lake management plan, 2011.

9. AZARNIVAND A., BANIHABIB M.E. A Multi-level Strategic Group Decision Making for Understanding and Analysis of Sustainable Watershed Planning in Response to Environmental Perplexities. Group Decision and Negotiation, 26 (3), 629, 2017.

10. BANIHABIB M.E., AZARNIVAND A., PERALTA R.C. A new framework for strategic planning to stabilize a shrinking lake. Lake and Reservoir Management, 31 (1), 31, 2015.

11. QASEMIPOUR E., ABBASI A. Virtual water flow and water footprint assessment of an arid region: A case study of South Khorasan province, Iran. Water (Switzerland), 11 (9), 1755, 2019.

12. BANIHABIB M.E., SHABESTARI M.H. Decision Models for the Ranking of Agricultural Water Demand Management Strategies in an Arid Region. Irrigation and Drainage, 66 (5), 773, 2017.

13. ALLAN J.A. Fortunately there are Substitutes for Water Otherwise our Hydro-political Futures Would be Impossible. Priorities for Water Resources Allocation and Management. Priorities for Water Resources Allocation and Management, 13, 13. Retrieved from http://www.ircwash.org/sites/default/files/210-93PR-11967. pdf\#page $=181992$.

14. DALIN C., WADA Y., KASTNER T., PUMA M.J. Groundwater depletion embedded in international food trade. Nature, 543 (7647), 700, 2017.

15. DU FRAITURE C. Does international cereal trade save water?: the impact of virtual water trade on global water use (Vol. 4). Iwmi, 2004.

16. SHI J., LIU J., PINTER L. Recent evolution of China's virtual water trade: Analysis of selected crops and considerations for policy. Hydrology and Earth System Sciences, 18 (4), 1349, 2014.

17. MASUD M.B., WADA Y., GOSS G., FARAMARZI M. Global implications of regional grain production through virtual water trade. Science of the Total Environment, 659, 807, 2019.

18. DALIN C., QIU H., HANASAKI N., MAUZERALL D.L., RODRIGUEZ-ITURBE I. Balancing water resource conservation and food security in China. Proceedings of the National Academy of Sciences, 112 (15), 4588, 2015.

19. ASAADI MEHRABANI M., BANIHABIB M.E., ROOZBAHANY A. Fuzzy Linear Programming Model for the Optimization of Cropping Pattern in Zarrinehroud Basin. Iran Water Resources Research, 14 (1), 13. Retrieved from http://iwrr.sinaweb.net/article_47468.html 2018.

20. BOSTANI F., MOHAMMADI H. Determining Optimal Operation Plan With Emphasis on Environmental Objectives in Fasa District: Application of Multi Objective and Fuzzy Programming. Agricultural Economics and Development, 19 (75), 1. Retrieved from http://aead.agriperi.ac.ir/article_58755.html 2018.

21. Ramsar Convention. Retrieved from http://www.ramsar. org 2013.

22. HÜFNER K. UNESCO-United Nations Educational, Scientific and Cultural Organization. In A concise encyclopedia of the United Nations (pp. 715-718). Brill Nijhoff, 2010.

23. AZARNIVAND A., BANIHABIB M. The Identification of Effective Factors of Strategic Implementation in Water Resources Management (Case Study: Lake Urmia Basin). Desert, 18 (2), 177, 2013.

24. FATHIAN F., MORID S., KAHYA E. Identification of trends in hydrological and climatic variables in Urmia Lake basin, Iran. Theoretical and Applied Climatology, 119 (3-4), 443, 2014.

25. Agricultural Renaissance by changing the pattern of cultivation in the catchment area. Retrieved from http:// www.ulrp.ir/fa// 2019.

26. KHAZAEI B., KHATAMI S., ALEMOHAMMAD S.H., RASHIDI L., WU C., MADANI K., AGHAKOUCHAK A. Climatic or regionally induced by humans? Tracing hydro-climatic and land-use changes to better understand the Lake Urmia tragedy. Journal of Hydrology, 569, 203, 2019.

27. KABIRI K., PRADHAN B., SHARIFI A., GHOBADI Y., PIRASTEH S. Manifestation of Remotely Sensed Data Coupled With Field Measured Meteorological Data for an Assessment of Degradation of Urmia Lake, Iran. In Advances in Biomedical Engineering, 2012.

28. KISI O., AZAD A., KASHI H., SAEEDIAN A., HASHEMI S.A.A., GHORBANI S. Modeling Groundwater Quality Parameters Using Hybrid Neuro-Fuzzy Methods. Water Resources Management, 33 (2), 847, 2019.

29. Ministry of energy of Iran. Updating water balance, 2012. 